\title{
Use of high-resolution DEM for improving stream slope estimates and its effect on modelled fine sediment loads
}

\author{
$\underline{\text { A. Pollett }}^{1}$ and B. Fentie ${ }^{2}$ \\ ${ }^{1}$ Queensland Department of Resources, Nambour, \\ ${ }^{2}$ Queensland Department of Environment and Science, Dutton Park \\ Email: angela.pollett@resources.qld.gov.au
}

\begin{abstract}
Stream slope is used in Great Barrier Reef (GBR) catchment models with the estimation of mean annual streambank erosion. Streambank erosion is the dominant erosion process in a number of GBR basins. Over low-relief terrain detailed high-resolution digital elevation model (DEM) data is required to resolve the subtle slopes and small landscape features such as levee banks and minor channels. Current stream slope estimates use a relatively coarse $(30 \mathrm{~m})$ resolution DEM. To improve the accuracy of slope estimates, a semiautomatic method has been developed to make use of available high-resolution (1m) LiDAR DEM data.

The revised slope estimates were implemented in the Burnett-Mary Region catchment model to evaluate their impact on modelled fine sediment supply from streambank erosion. These changes in stream slope resulted in a $16 \%$ reduction in modelled streambank erosion supply of fine sediment. The use of high-resolution LiDAR DEM provided a superior level of accuracy, detail and confidence for stream slope calculation when compared to the use of low-resolution DEM data, particularly over short stream reaches and low-relief landscapes. Where available, finer-resolution topographic data such as LiDAR can be used to improve model parameterisation and increase confidence in the modelling of sediment from streambank erosion.
\end{abstract}

Keywords: $\quad$ Stream slope, streambank erosion, LiDAR, DEM, Great Barrier Reef 


\section{INTRODUCTION}

\subsection{The use of DEM in GBR catchment models}

Paddock to Reef (P2R) catchment models use the eWater Source modelling framework with Dynamic SedNet as a plug-in to estimate fine sediment and nutrient generation, loss, and transport processes across GBR catchments (McCloskey et al. 2021). The model operates at the subcatchment-level $\left(30-50 \mathrm{~km}^{2}\right)$ with estimates generated for functional units (land uses) within each subcatchment. DEM data is a fundamental input used to derive slopes, model subcatchment boundaries, drainage networks (links) and outlets (nodes). The Dynamic SedNet model plugin is used to calculate hillslope, gully and stream bank erosion. This work focuses on the accurate calculation of stream slope which is a key input for the estimation of stream bank erosion.

Stream slope (Equation 1), also referred to as 'river bed slope' $(\mathrm{m} / \mathrm{m})$ is one of several metrics used in the estimation of stream bank retreat rate. The retreat rate is used with mass conversion and bank erodibility to calculate mean annual stream bank erosion in the Dynamic SedNet Streambank Parameteriser (Ellis, R 2017).

$$
\text { Stream Slope }(\%)=\frac{(\text { Maximum }(\text { Elevation })-\text { Minimum }(\text { Elevation }))}{\text { Stream Length }}
$$

GBR catchment models have used the one arc-second (approx. 30m cell size) Shuttle Radar Terrain Mission hydrologically enforced digital elevation model (SRTM DEM-H) sourced from Geoscience Australia (Gallant et al. 2011) to derive subcatchments, links and nodes as well as calculate stream slope. This DEM data provided the best-available, consistent elevation data coverage for the whole GBR catchment.

\subsection{Issues with use of coarse resolution DEMs}

The use of a relatively coarse resolution DEM reduces model reliability in locations where the scale and accuracy of the data is unable to adequately represent landscape complexity and flow direction as required for catchment-scale modelling. The required level of detail changes across the landscape, with low relief terrain being more sensitive to spatial data inaccuracy than steeper terrain as flow direction becomes more reliant on the detection of a smaller magnitude change in elevation. Coarser resolution grids with larger cell sizes have the effect of smoothing terrain and reducing representation of small or narrow linear features, such as streams with a narrow incision.

Wu et al. (2008) 'showed that both DEM grid size and vertical accuracy could have profound effect on hydrologic modelling performance.' Concluding 'An optimum DEM grid size (or a range) exists for a hydrologic model application with raster GIS, which can render most optimum results in prediction. The grid size would depend much on terrain complexity of the study site and topographic attributes used in the particular model.' (Wu et al. 2008). In the GBR the issue with river slope gradient was noted by Prosser (2018) indicating, 'There are problems with estimating low gradient river slopes from coarse resolution DEMs. DEM construction methods using splines produce artefacts in stream slope to which stream power calculations are quite sensitive (see Wilkinson et al. 2006; Bartley et al. 2008).'

\subsection{LiDAR DEM availability and accuracy}

Over recent years LiDAR data has been captured over parts of the GBR catchment with coverage predominantly over the eastern coastal regions, particularly urbanised areas and arable farmland including landscapes dominated by large low relief floodplains.

Horizontal and vertical accuracy statements for the SRTM DEM-H and LiDAR datasets clearly indicate that the LiDAR offers a higher resolution and more accurate foundation on which to measure slope values (Table 1). The upgrade in vertical accuracy from $+/-3.9 \mathrm{~m}$ (SRTM) to $+/-0.3 \mathrm{~m}$ (LiDAR) provides a 13-fold improvement in vertical accuracy. The LiDAR data is particularly useful over floodplains where the accurate measurement of elevation change for stream slope commonly requires sub-metre accuracy. 
Pollett and Fentie, Use of high-resolution DEM for improving stream slope estimates...

Compared to coarser scale DEMs, LiDAR DEM provides a wealth of information with most streams being represented by stream bed and banks, plus a range of discernible in-stream features such as rock outcrops, sand banks and islands. However, the increased level of detail also creates challenges when using LiDAR DEM for calculation of stream slope as these in-stream features can become obstacles to capturing a representative stream height value, especially over short flat reaches of a stream where the relatively small change in elevation required for slope calculation is particularly sensitive to inaccuracies.

Table 1. SRTM DEM-H and LiDAR DEM spatial resolution and accuracy

\begin{tabular}{|l|l|l|l|l|}
\hline Dataset & Cell Size & $\begin{array}{l}\text { Horizontal } \\
\text { Accuracy }\end{array}$ & Vertical Accuracy & Notes \\
\hline $\begin{array}{l}\text { SRTM DEM-H } \\
\text { 1" }\end{array}$ & $25 \mathrm{~m}$ & $+/-7.2 \mathrm{~m}(90 \% \mathrm{CI})^{1}$ & $+/-9.8 \mathrm{~m}(90 \% \mathrm{CI})^{1}$ & $\begin{array}{l}\text { Elevation error decreases } \\
\text { over flat areas to }+/-3.8 \mathrm{~m}\end{array}$ \\
\hline LiDAR DEM & $1 \mathrm{~m}$ & $+/-80 \mathrm{~cm}(95 \% \mathrm{CI})^{2}$ & $+/-30 \mathrm{~cm}(95 \% \mathrm{CI})^{2}$ & $\begin{array}{l}\text { Terrestrial LiDAR is } \\
\text { unreliable over water }\end{array}$ \\
\hline
\end{tabular}

${ }^{1}$ Accuracy statement for Australia-wide dataset (Gallant et al. 2011)

${ }^{2}$ LiDAR project datasets vary in reliability, the Bundaberg 2016 dataset (DNRME, 2016) indicates a typical level of accuracy

An inherent limitation with terrestrial LiDAR data is the lack of reliable data over water bodies due to the absorption and attenuation of the infrared light signal in water that is used to measure height. In recent years hydro-flattening has been used to replace the spurious irregular values over waterbodies with a flat surface. Data gaps occur over larger water bodies as LiDAR is not collected over these areas. Additional LiDAR DEM limitations included poor-quality data areas that occurred due to dense vegetation cover (e.g., dense riparian vegetation) or crop cover (e.g., mature sugarcane) where signal penetration has been reduced and ground heights not accurately resolved. Given these issues, measurement of slope was limited to the water edge and not to the base of the stream (riverbed slope) with a manual checking process used when extracting stream elevation values to ensure spurious, erroneous or gap areas in the data were avoided.

\section{GIS METHOD FOR CALCULATING STREAM SLOPE}

The new semi-automatic method of stream slope estimation from LiDAR DEM is now described with work focused over low relief areas where an improved slope estimate will be of most benefit. The initial part of the process was manual and time-consuming but required to ensure extraction of accurate slope values properly aligned to the model subcatchments. The method also makes use of watercourse polygon mapping that was used to derive stream centrelines for the estimation of stream length and this work is also briefly described. ESRITM ArcGIS Pro ${ }^{\circledR}$ software version 2.5.2 was used for all aspects of the GIS work including the storage, editing, processing and presentation of spatial data.

The GBR catchment models were built using the STRM DEM-H raster with subcatchments and streams generated with a headwater threshold of $30 \mathrm{~km}^{2}$ to $50 \mathrm{~km}^{2}$ to represent the inflow area for a reach of stream. Stream reaches were assigned a straight-line schematic representation referred to as a model link with a stream slope value estimated. The GBR model data also included representation of the end points of the links referred to as link nodes. It is a modified copy of the model nodes that was used to capture the required minimum and maximum height values from the LiDAR DEM within each subcatchment.

\subsection{LiDAR DEM data sources used}

Queensland Government Spatial Portal (Q1d Gov 2020) DEM time-series layer, which is a collation of the SRTM DEM-H and LiDAR DEM project data, was used with some areas having multiple time periods of LiDAR data coverage. This data was accessed via a Portal connection in the ESRITM ArcGIS Pro ${ }^{\circledR}$ software package. The Portal data was used where possible as it provided easy access to the LiDAR height data however in some areas locally held LiDAR DEM mosaics were used to supplement coverage.

\subsection{Manual checking and realignment of node points}

The GIS method for calculating stream slope relied on the accurate location of outlet nodes which were used to spatially intersected with the DEM to capture elevation values. The manual part of the process involved 
cross-checking the node location against DEM and imagery to interpret the landscape features and ensure that a suitable location was selected to represent stream height. The nodes needed to be located close to the stream to ensure the elevation value is as representative as possible of the stream height and not taken from a spurious area over water or a higher location outside the in-stream area, such as the top of stream bank that would artificially raise the elevation of the stream at that point.

An additional requirement when locating the nodes was to ensure that they were within a small nominal buffer distance (e.g., 70m) of all relevant subcatchment boundaries. This was done so a buffered area around the node point could be used to spatially overlap and intersect the elevation data with all relevant subcatchment(s) (Figure 1). The nominated buffer distance needed to be small enough to ensure that only the required subcatchments were intersected, excluding adjacent stream subcatchments. Leaf nodes (stream headwaters) and outlet nodes (approx. river mouth) were an exception because the proximity to neighbouring subcatchments was not an issue as they were headwater or end of system nodes. In a few cases the nodes were duplicated where the stream and all relevant subcatchments did not all fit with the nominated buffer distance. In the case of node duplication, the nodes then needed to be located outside the nominated buffer distance to ensure that only two buffered nodes (minimum \& maximum elevation) overlapped each subcatchment.

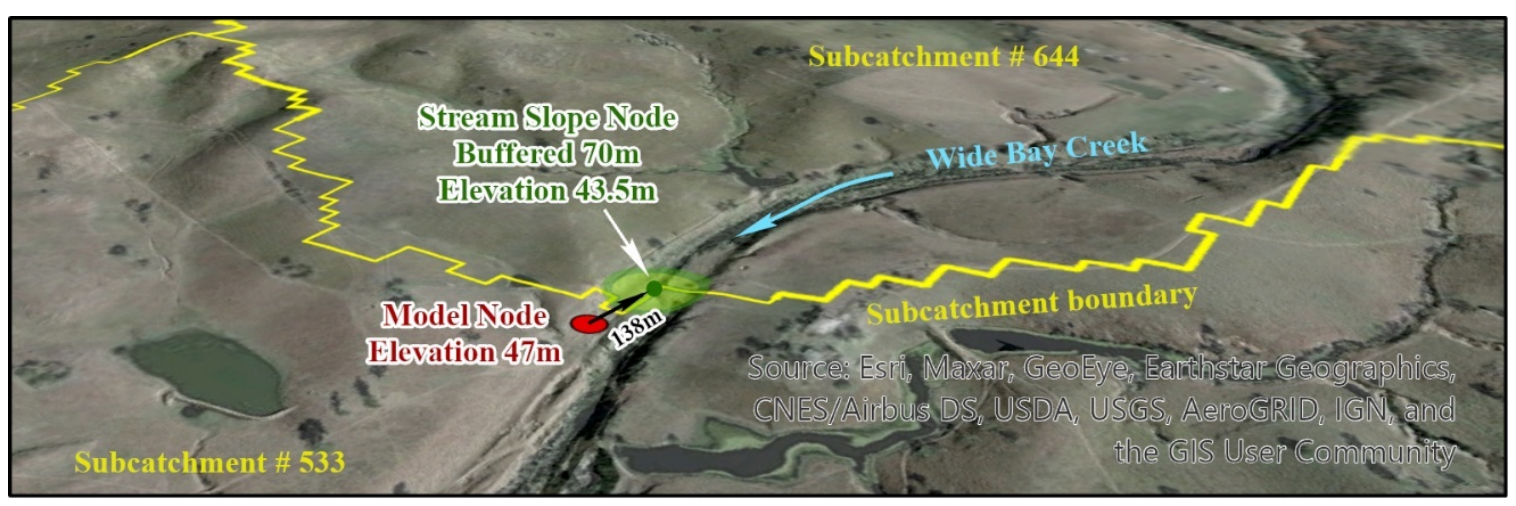

Figure 1. Illustration of node relocation from above the river bank to the water's edge whilst keeping within the node buffer distance to ensure overlap with both the upstream and downstream subcatchments.

Revision of the stream slope also provided the opportunity to review how dams, lakes and weirs were represented. As water flow is slowed or stopped by in-stream impoundments, stream power is reduced/lost, and sediment deposited with reduced opportunity for remobilisation. Therefore, dam height was excluded from stream slope calculation with the node duplicated and relocated as follows:

- Elevation for the inflow subcatchment is measured above the dam/weir and

- Elevation for the outflow subcatchment is measured below the dam/weir.

\subsection{Automatic calculation of elevation difference}

After checking \& finalising alignment of the node points to the DEM \& subcatchments, the ArcGIS Spatial Analyst tool 'Extract multivalues to points' was used to extract the LiDAR DEM height value at the node point location. The elevation difference was then calculated for each subcatchment with the spatial data processing done using ArcGIS Model Builder. The three main steps in the model were: (1) buffer the node points the nominal distance (e.g., 50m); (2) spatially intersect subcatchments with the buffered points to join the elevation values to the subcatchments; and (3) use the ArcGIS 'Summary Statistics' tool to summarise the minimum and maximum elevation value by subcatchment. The statistics frequency value was used to flag any subcatchments with more than two overlapping buffered nodes and the spatial location of these nodes was reviewed and if required, the node position was adjusted and the model re-run.

\subsection{Stream length calculation}

Stream length was calculated from watercourse polygon centrelines that were generated using the ArcGIS Production Centreline tool. The (Topographic) Production Mapping ArcGIS extension was required to run 
Pollett and Fentie, Use of high-resolution DEM for improving stream slope estimates...

the Centreline tool from the Generalization Toolbox. Calculation of stream length by subcatchment was achieved by intersecting the stream centrelines with the model subcatchments.

\subsection{Linking of stream elevation and length, and calculation of stream slope}

Tabular data listing minimum and maximum elevation for each subcatchment (2.3) was linked to the table of stream lengths (2.4) using the 'Join Field' tool with the unique subcatchment number as the join field. Stream slope was then calculated as the elevation difference divided by the stream length (Equation 1). This tabular data was subsequently joined back onto the spatial data using the ArcGIS 'Add Join' tool to enable the spatial visualisation and validation of stream slope values.

A default slope value of 0.00001 (1E-05) was assigned to any subcatchments on floodplain areas with a zeroheight difference (e.g. due to hydro-flattening) as these streams were typically flatter than most other streams and so should be assigned a relatively very small slope value. This replaces the previous default value of 0.000001 (1E-06). The new default slope value of 1E-05 was assigned as this equates to an elevation change of $1 \mathrm{~m}$ over $100 \mathrm{~km}$, which is comparable with the minimum stream slope values typically found over GBR floodplains according to LiDAR DEM based stream slope estimates calculated for the GBR Wet Tropics and Mackay Whitsunday NRM Regions.

\section{IMPLEMENTATION AND EVALUATION OF REVISED STREAM SLOPE IN BURNETT MARY (BM) CATCHMENT MODEL}

The BM NRM Region is the most southern region in the GBR catchment covering $51722 \mathrm{~km}^{2}$. The P2R Source Dynamic SedNet model for the BM region includes the Burnett, Mary, Baffle, Kolan and Burrum basins. The two largest catchments, the Burnett River (33 $\left.257 \mathrm{~km}^{2}\right)$ and the Mary River $\left(9433 \mathrm{~km}^{2}\right)$ discharge into Hervey Bay at the southern tip of the GBR Marine Park. Accurate estimation of streambank erosion is particularly relevant in the Mary basin given that it is the dominant source of fine sediment for the area and identified as 'one of the five highest contributors of fine sediment of the 35 catchments that drain to the Great Barrier Reef.' (State of Queensland, Queensland, 2018). This work was focused over the relatively flat low relief coastal floodplain areas with more porous and erodible geologies.

The Burnett Mary regional catchment model was used to evaluate the change in modelled bank erosion estimates comparing the use of stream slopes determined from STRM DEM-H against streams slopes determined from LiDAR DEM (Table 2, Figures 2 and 3). Stream slopes were assigned to model links by subcatchment number.

Table 2. Comparison of the BM modelled annual stream bank erosion fine sediment (FS) supply load (kt/y)

\begin{tabular}{|l|r|r|c|}
\hline Basin & \multicolumn{1}{|c|}{ STRM-DEM-H stream slopes } & LiDAR-DEM stream slopes & Change (\%) \\
\hline Baffle & 5.6 & 3.8 & -32 \\
\hline Burnett & 256.5 & 196.6 & -23 \\
\hline Burrum & 3.3 & 2.9 & -13 \\
\hline Kolan & 16.9 & 10.3 & -39 \\
\hline Mary & 427.0 & 381.4 & -11 \\
\hline BM Total & 709.2 & 595.0 & -16 \\
\hline
\end{tabular}

When evaluating the impact of stream slope changes on stream bank erosion estimates it was necessary to take into account that the erosion values were calculated using a combination of factors including stream slope, stream bank erodibility, vegetation cover, stream length, and bank height with the overall effect of changing stream slope depending on all these factors. For example, an increase in stream slope will produce more erosion on more erodible soils when compared to the same magnitude of slope increase for less erodible soils. So although the improvement of stream slope estimates are of value, the ultimate goal is to improve accuracy across all relevant factors to in order to effectively refine catchment-scale bank erosion estimates and inform better riverine management outcomes. Sensitivity analysis of the impact of changes in each input (variable) on modelled streambank erosion is beyond the scope of this paper. 
Following an analysis of all stream slope data for the Burnett Mary model the following changes were made to the model:

- 302 out of a possible 682 stream slopes were modified. Of these, 187 slopes decreased while the remaining 115 slopes increased.

- Prior to slope changes, 56 had a minimum default slope of 0.000001 and post slope changes this decreased to 35 , resulting in 21 links having a default value replaced with a measured slope value.

- Streambank erosion supply of fine sediment was reduced by $16 \%$. The largest reduction was $39 \%$ in the Kolan Basin followed by $32 \%$ in the Baffle Basin.

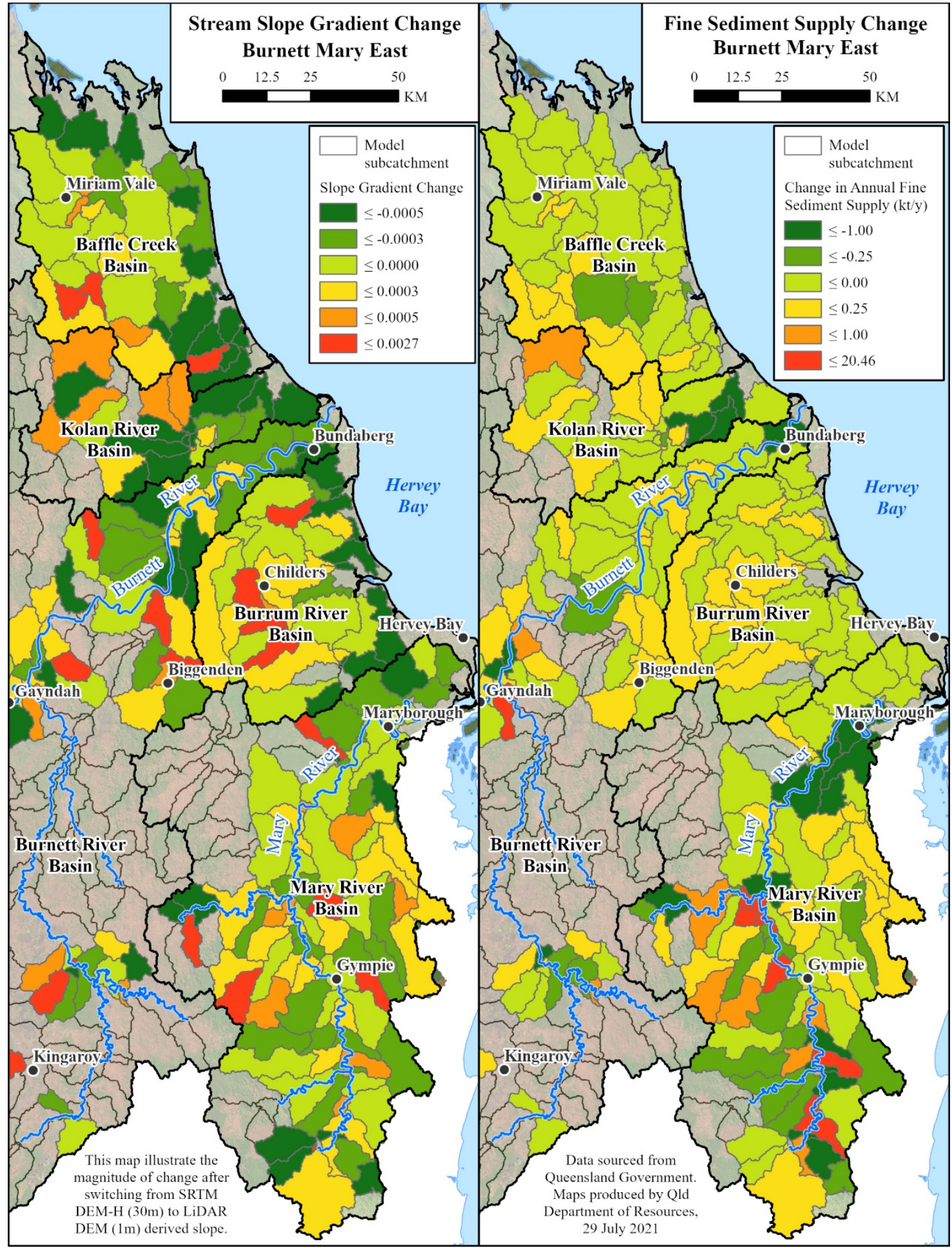

Figure 2. Stream slope change

Figure 3. Streambank erosion change 


\section{DISCUSSION AND VALIDATION}

As the level of detail used to represent stream geometry increases, the level of complexity with extracting and validating derived slope values also increases. Although the LiDAR DEM clearly provided a superior level of detail and accuracy over the SRTM DEM-H, the accurate calculation of stream slope also relied on navigating through the 'flood of data' to extract suitable elevation values for slope calculation.

Independently collected and validated stream slope data was generally not available to support detailed evaluation of results. Nevertheless, comparison against topography did provide a practical common-sense guide to ensure that stream slope values were logical and fitted the local landscapes with steeper slopes located in the more rugged terrain. Any inconsistent values were cross-checked against the LiDAR DEM data to ensure selected height values were acceptable and stream slopes were logical when compared with surrounding values and comparable landscapes. Stream slope accuracy was most sensitive to low slope gradients and short stream lengths with the LiDAR data providing most value in these areas.

\section{CONCLUSION}

The use of high-resolution LiDAR DEM for stream slope calculation provided a superior level of accuracy, detail and confidence when compared to the use of low-resolution DEM data, particularly over short stream reaches and low-relief landscapes with subtle stream slopes. The method presented here makes best use of available LiDAR coverage using a combination of spatial tools and expert knowledge that allows for data limitations with an approach that is semi-automated, transparent and repeatable. The detailed review of stream slopes has contributed towards more consistent and informed slope estimates, an improved estimate of minimum default slope values and a better understanding of the LiDAR data application and limitations. This work contributes to improving the spatial data underpinning the GBR catchment models.

\section{REFERENCES}

Bartley, R, Keen, RJ, Hawdon, AA, Hairsine, PB and Disher, MG 2008, Bank erosion and channel width change in a tropical catchment. Earth Surface Processes and Landforms, 33: 2174-2200.

Ellis, R 2017, 'Dynamic SedNet Component Model Reference Guide : Update 2017 Concepts and algorithms used in Source Catchments customisation plugin for Great Barrier Reef catchment modelling. Queensland Department of Environment and Science, Bundaberg, Queensland.

Gallant, J.C., Dowling, T.I., Read, A.M., Wilson, N., Tickle, P., Inskeep, C. (2011) 1 second SRTM Derived Digital Elevation Models User Guide. Geoscience Australia

www.ga.gov.au/topographic-mapping/digital-elevation-data.html

Mccloskey, GL, Baheerathan, R, Dougall, C, Ellis, R, Bennett, FR, Waters, D, Darr, S, Fentie, B, Hateley, LR \& Askildsen, M 2021, 'Modelled estimates of fine sediment and particulate nutrients delivered from the Great Barrier Reef catchments', Marine Pollution Bulletin, vol. 165, no. July 2020, p. 112163, accessed from $<$ https://doi.org/10.1016/j.marpolbul.2021.112163 $>$.

Prosser, Ian P (2018). Improving how gully erosion and river sediment transport processes are represented in Queensland catchment models. Report to Queensland Water Modelling Network, Dept. Environment \& Science.

Queensland Government Open Data Portal (2020) https://www.resources.qld.gov.au/home/about-us/opendata

Queensland, 2018. Reef 2050 Water Quality Improvement Plan 2017-2022 (State of Queensland, Brisbane).

Wilkinson, SN, Prosser, IP and Hughes, AO 2006, Predicting the distribution of bedload accumulation using river network sediment budgets. Water Resources Research, 42, W10419. 10.1029/2006WR004958. 